\title{
O diálogo como possibilidade de mediação da violência na escola
}

\section{Dialogue as a possibility to mediate violence in schools}

\section{El diálogo como posibilidad de mediación de la violencia en la escuela}

\author{
Jean Mac Cole Tavares Santos* \\ Paula Janaina Meneses Rodrigues ${ }^{* *}$
}

\begin{abstract}
Resumo: A violência na escola é compreendida como um fenômeno de diferentes faces que faz parte da dinâmica cultural e social da escola. Ela deve ser gerida pelos professores através da postura dialógica apontada por Freire (1987), subsidiada pelo diálogo proposto por Bohm (1989, 1999) e Bakhtin (1997 apud NAVARRO, 2005). Com isso, o presente trabalho teve como objetivo analisar a contribuição do diálogo para a mediação da violência escolar, através de uma pesquisa qualitativa, com aplicação de questionários semiestruturados e tendo como aporte teórico: Abromavay et al. (2002), Andrade (2011), Derbabieux (2002), Cabrale Lucas (2010), Sposito (1998), Freire (1987), Bohm (1989) e Navarro (2005). O presente estudo demonstrou que a partir do diálogo, os docentes podem desenvolver a Competência Inter-Relacional (CIR) que contribui para a construção de uma educação dialógica voltada para a transformação social e para a mediação da violência na escola. Um diálogo que permite maior interação entre os sujeitos escolares, melhorando a convivência no ambiente escolar.
\end{abstract}

Palavras-chave: Dialogicidade. Gestão de conflitos. Ambiente escolar.

\begin{abstract}
Violence in schools is understood as a phenomenon of different faces which is part of the cultural and social dynamics of the school. It must be managed by teachers through the dialogical posture pointed out by Freire (1987), supported by the dialogue proposed by Bohm (1989, 1999) and Bakthin (1997 apud NAVARRO, 2005). Thus, this study aimed to analyze the contribution of dialogue to the mediation of violence in schools, through qualitative research, applying semi-structured questionnaires. The theoretical support comes from Abromavay et al. (2002), Andrade (2011), Derbabieux (2002), Cabrale Lucas (2010), Sposito (1998), Freire (1987), Bohm (1989) and Navarro
\end{abstract}

\footnotetext{
* Professor do Programa de Pós-Graduação em Educação da Universidade do Estado do Rio Grande do Norte - UERN. E-mail: <maccolle@hotmail.com>

** Mestranda do Programa de Pós-Graduação em Educação da Universidade do Estado do Rio Grande do Norte - UERN. E-mail: <janaguelsonkadu@hotmail.com>
} 
(2005). Results of the study show that from dialogue, teachers can develop Interrelational Competence (IRC) which contributes to the construction of a dialogical education towards social transformation and mediation of the violence in schools. Using dialogue, which permits better interaction between school individuals, tends to improve life in the school environment.

Keywords: Dialogicity. Conflict management. School environment.

Resumen: La violencia en la escuela está comprendida como un fenómeno de diferentes caras que forma parte de la dinámica cultural y social de la escuela. Esta debe ser gestionada por los profesores a través de la postura dialógica indicada por Freire (1987), subsidiada por el diálogo propuesto por Bohm $(1989,1999)$ y Bakhtin (1997 apud NAVARRO, 2005). Con eso, el presente trabajo tuvo como objetivo analizar la contribución del diálogo para la mediación de la violencia escolar, a través de una investigación cualitativa, con aplicación de cuestionarios semiestructurados y teniendo como aporte teórico: Abromavay et al. (2002), Andrade (2011), Derbabieux (2002), Cabrale Lucas (2010), Sposito (1998), Freire (1987), Bohm (1989) y Navarro (2005). El presente estudio demostró que a partir del diálogo, los docentes pueden desarrollar la Competencia Inter-Relacional (CIR) que contribuye para la construcción de una educación dialógica orientada a la transformación social y a la mediación de la violencia en la escuela. Un diálogo que permite mayor interacción entre los sujetos escolares, mejorando la convivencia en el ambiente escolar.

Palabras clave: Dialogicidad. Gestión de conflictos. Ambiente escolar.

\section{Introdução}

A sensação de violência e o medo são frutos do estado de violência que marca fortemente a sociedade moderna. Uma modernidade caracterizada pela fragilidade dos relacionamentos humanos e pela crescente individualidade, onde cada ser humano basta em si mesmo e o privado se sobrepõe ao coletivo (BAUMAN, 2001). Viver a modernidade líquida de Bauman significa conviver com diferentes tipos de medos, que transitam de acordo com a incerteza e a fluidez da dinâmica social carente de segurança e proteção.

No ambiente líquido moderno, [...] a luta contra os medos se tornou tarefa para a vida inteira, enquanto os perigos que os deflagram - ainda que nenhum deles seja percebido como inadministrável - passaram a ser considerados companhias permanentes e indissociáveis da vida humana. Nossa vida está longe de ser livre do medo, e o ambiente-líquido moderno em que tende a ser conduzida está longe de ser livre de perigos e ameaças. (BAUMAN, 2008, p. 15).

Além dos medos de ameaças rotineiras, compartilhamos o estado de medo derivado, que, aumentado pela sensação de que as ameaças podem atingir, aleatória e imprevisivelmente, cada um, em qualquer momento, influencia comportamentos e escolhas. Mesmo que não haja ameaça iminente, muitas vezes 
condicionamos nossas atitudes a esse quadro geral, contribuindo para a ideia de caos, de insegurança, de estado permanente de medo.

A escola, instituição fulcral na sociedade, participa desse panorama da modernidade líquida, principalmente em relação ao aumento do estado de medo. Mesmo não implicando aumento da violência real, há ampliação da sensação de insegurança dentro da escola,redimensionando significativamente os casos de violência. Segundo Teixeira e Porto (1998, p. 57),

Cada ação concreta de agressão ou violência permite ritualizar uma ameaça, justificando a reprodução do medo e a adoção de medidas de segurança. Mas, paradoxalmente, essas medidas acentuam a insegurança e o medo e provocam novas formas de geri-los, seja na sociedade, seja na escola.

A violência na escola, nessa conotação plural, como se vê, não é um fenômeno recente. Os estudos sobre a temática apontam que ela também é fortemente influenciada pela violência externa. Debarbieux (2002), por exemplo, afirma que a violência escolar é marcada por aspectos endógenos e exógenos, isto é, por questões de natureza interna e externa à escola, envolvendo processos sociais mais amplos. Refletir sobre a violência na escola, assim, significa pensar na dinâmica escolar e de como podemos mediar essa violência melhorando o ambiente de aprendizagem.

Novidade no debate sobre violência, porém, é a dimensão biaxial dela na sociedade moderna líquida. Isso não significa dizer, simploriamente, que a violência na escola seja somente sensação de ou medo dela. Significa mais que a situação de violência toma novos contornos, envolvendo-a em si e o sentimento social do estado que ela desencadeia. Em outras palavras, não devemos enfrentar a questão somente em seus movimentos reais. Precisamos enfrentar o medo como um aspecto real da situação de violência.

Dessa forma, quando aludimos o termo violência, chamamos para o debate os eventos violentos e as sensações, estado de medo, produzida pela possibilidade de violência. Ambas, com efeito, são violências. Tudo isso significa, enfim, que os dois fenômenos na verdade revelam-se em somente um, a violência. Esta precisa ser compreendida, enfrentada, superada em prol da construção de um ambiente escolar pedagogicamente eficaz. Com esse entendimento, prosseguimos.

Nos dois casos, de violência real e do estado de medo dela, um ambiente escolar violento influencia no desenvolvimento das atividades pedagógicas e, consequentemente, no aprendizado dos alunos, podendo implicar maior fracasso escolar. Assim, com a ampliação da violência pelo estado de medo, a degradação das relações na escola se evidencia, comprometendo a importância da educação e da escola para a formação humana. Por isso, compreender os diferentes 
tipos de violência como algo que faz parte da dinâmica social é essencial para nos aproximarmos de alternativas positivas de seu enfretamento.

Acreditamos que a postura dialógica proposta por Freire (1987), apoiada pela dialogia de Bohm $(1989,1999)$ e de Bakhtin (1997 apud NAVARRO, 2005), fornece importantes subsídios para a mediação da situação de violência na escola. Postura baseada no diálogo permanente entre os sujeitos escolares, através da problematização e da reflexão sobre a realidade, onde o conhecimento é construído com a participação ativa de todos os sujeitos do processo. Processo que possibilita refletir sobre a realidade, buscando a conscientização dos sujeitos para o desenvolvimento de uma práxis social, em busca da transformação da situação de violência na escola.

Assim, neste trabalho, temos como principal objetivo analisar a contribuição do diálogo na mediação desse quadro de violência. Para tanto, realizamos pesquisa de natureza qualitativa, com aplicação de questionário semiestruturado com seis professores (codificados em P1, P2, P3, P4, P5 e P6) de duas escolas públicas estaduais de Ensino Médio do município de Mossoró. Os três primeiros professores são da Escola Abel Freire Coelho e os três últimos são da Escola Aída Ramalho; quatro são do sexo feminino e dois do sexo masculino. Os docentes depoentes têm bastante tempo de sala de aula e de experiência no Ensino Médio, em média 20 anos de profissão. Vivência escolar que ficou claramente demonstrada nas respostas ao questionário, através da clareza e da qualidade dos exemplos que apresentaram para a descrição do cotidiano de suas escolas.

As escolas escolhidas, de Ensino Médio, possibilitam um olhar na modalidade de ensino que tem adquirido grande importância social, local privilegiado para estudo da juventude em idade escolar, malgrado ainda tenhamos boa parte da juventude longe da escola. Porém, de fato, o Ensino Médio, etapa final da Educação Básica, tem recebido atenção especial na sociedade contemporânea, sendo alvo de investimentos significativos, com ampliação de escolas e de matrículas como nunca antes visto na história da educação brasileira (ZIBAS, 2002).

Segundo sua nova identidade, unitária, a escola de Ensino Médio deve aliar o ensino propedêutico à formação profissional através da educação dialógica. Como determina a Lei de Diretrizes e Bases da Educação (LDB) de 1996, o Ensino Médio precisa trabalhar a formação integral dos educandos, com a finalidade de desenvolver todas as suas potencialidades nas dimensões: intelectual, afetiva, física, ética, estética, política, social e profissional; além de prepará-los para o exercício da cidadania e para o mundo do trabalho.

Brasil (2008) aponta a importância do diálogo com a juventude e as perspectivas dos jovens relativas à escola e o seu projeto pedagógico, o que influencia diretamente na melhoria do ambiente escolar e no combate à situação 
de violência na escola. Confirmando a importância desse diálogo, as Diretrizes Curriculares Nacionais para o Ensino Médio (DCNEM) apontam que

A última etapa da Educação Básica precisa assumir, dentro de seus objetivos, o compromisso de atender, verdadeiramente, a todos e com qualidade, a diversidade nacional com sua heterogeneidade cultural, de considerar os anseios das diversas juventudes formadas por adolescentes e jovens que acorrem à escola e que são sujeitos concretos com suas múltiplas necessidades. (BRASIL, 2011, p. 29).

Essa nova concepção de Ensino Médio pressupõe uma escola dialógica que trate os alunos na sua complexidade, como seres de vontades e desejos, não como objetos, depósitos de informações. Os Parâmetros Curriculares Nacionais para o Ensino Médio (PCNEM), reforçando a mesma ideia, afirmam que a formação dos alunos deve ter como finalidade "o desenvolvimento de capacidades de pesquisar, buscar informações, analisá-las e selecioná-las; a capacidade de aprender, criar, formular, ao invés do simples exercício de memorização" (BRASIL, 2000, p. 5). Diante de tais pressupostos, pensar a relação dialógica como mediadora de conflitos no Ensino Médio é elemento da política educacional dessa modalidade de ensino. Vale, então, ouvirmos os sujeitos que atuam nas escolas buscando entender a contribuição do diálogo na mediação da violência na escola.

Para dar conta dessa problemática, optamos pela pesquisa qualitativa. Acreditarmos que "a abordagem qualitativa de um problema, justifica-se, sobretudo, por ser uma forma adequada para entender a natureza de um fenômeno social" (RICHARDSON, 2010, p. 79). Por lidarmos com seres humanos, trabalhamos com o "universo dos significados, dos motivos, das aspirações, das crenças, dos valores e das atitudes”. (MINAYO, 2009, p. 21).

Por isso, buscando aprofundar o conhecimento do fenômeno da violência na escola, o questionário foi composto de nove questões que visavam compreender a visão dos docentes sobre a violência na escola, o comportamento deles diante dos casos de violência, como ela intervém no cotidiano escolar e qual a postura da escola diante disso.

A análise das respostas dos questionários foi realizada através de alguns elementos da análise do discurso descrita por Orlandi (2005). Segundo a autora:

A análise do discurso não estaciona na interpretação, trabalha seus limites, seus mecanismos, como parte dos processos de significação. Também não procura um sentido verdadeiro através de uma "chave" de interpretação. Não há esta chave, há método, há construção de um dispositivo teórico. Não há uma verdade oculta atrás do texto. Há gestos que o constituem e que o analista, com seu dispositivo, deve ser capaz de compreender. (ORLANDI, 2005, p. 26). 
Com base na análise do discurso, podemos compreender os sentidos produzidos pelo texto, como ele se relaciona com o contexto em que foi produzido e qual a ideia presente naquele discurso, pois a linguagem se constitui por intermédio das relações sociais, sendo também parte integrante destas. Para Oliveira (2008, p. 16),

A linguagem apenas emerge em relações intersubjetivas, em determinadas condições e, assim sendo, é no processo de interação verbal que o signo linguístico, em qualquer de suas dimensões, reflete e refrata os valores dessa realidade, ou seja, tornando-se um indicador sensível e constitutivo das mudanças sociais.

Os sentidos de um determinado discurso estão relacionados com múltiplos fatores, tanto com o que é dito de maneira explícita ou implícita, as condições de sua produção, intenções do sujeito, o que poderia ter sido dito e não foi, quanto com outros discursos que já foram proferidos sobre o determinado tema. Essa pluralidade do discurso é confirmada por Navarro (2005) quando discorre sobre o diálogo de Bakhtin (1997 apud NAVARRO, 2005). Segundo a autora, para Bakhtin, todo discurso é dialógico, pois o eu pressupõe a existência do outro, "o discurso leva e traz consigo o já dito e o não dito, o passado e o futuro, o oculto e o descoberto" (NAVARRO, 2005, p. 59).

Procuramos encontrar nos discursos dos docentes todos os apagamentos, as contradições, os implícitos, os explícitos e a ideologia presente, isto é, todos os aspectos que representassem o contexto de violência de suas escolas. Pegamos as respostas do questionário e analisamos o que foi dito através de paráfrases. Dessa forma, observamos de que maneiras aquilo poderia ter sido dito e procuramos desvendar o porquê daquela formação discursiva. Assim, tentamos encontrar as marcas linguísticas que integram à formação discursiva de nosso aporte teórico, interpretando e compreendendo os sentidos ali relacionados.

$\mathrm{Na}$ organização deste artigo, inicialmente, discutimos o conceito de violência na escola apresentado pelos professores pesquisados e pelo aporte teórico de Abramovay et al. (2002), Debarbieux (2002), Cabral e Lucas (2010) e Sposito (1998), a fim de aproximar uma definição significativa para os agentes que atuam na escola, de ampliar a compreensão do fenômeno e de ver como este interfere no cotidiano escolar. Em seguida, discutimos também o conceito de diálogo proposto por Bohm (1989), Freire (1987) e Bakhtin (1997 apud NAVARRO, 2005) com o objetivo de aprofundar o conhecimento sobre a dialogia e o desenvolvimento de uma educação dialógica com o escopo de possibilitar a mediação da violência na escola.

Por fim, relacionando a análise dos questionários com o aporte teórico estudado procuramos entender também como a Competência Inter-relacional 
(CIR) descrita por Andrade (2011), pode contribuir para mediar os casos de violência na escola e propiciar a formação de uma postura dialógica dos professores e da escola.

\section{Delineando um conceito de violência}

Abramovay et al. (2002) realizou uma ampla pesquisa nacional procurando caracterizar os diferentes tipos e estágios da violência na escola. Para a autora, o conceito de violência na escola varia conforme o status e o local de quem fala, por isso não há um conceito unívoco. Afirma também que ao longo dos anos os estudos sobre a temática apontaram diversos caminhos.Inicialmente eram aliados a questões de indisciplina ou de delinquência juvenil, hoje a violência na escola também é associada a questões mais amplas, como a globalização e a exclusão social.

Fatores familiares, psicológicos, econômicos, sociais e circunstanciais devem ser considerados quando analisamos a violência escolar; são fatores de risco que influenciam no comportamento das vítimas e agressores. Entretanto, não devemos tratá-los de maneira determinista; não é pelo fato de uma escola estar localizada num bairro violento que terá casos de violência, nem muito menos é verdade que a escola não terá violência por estar num local dito seguro. Geralmente, estamos acostumados a associar pobreza com violência, mas nem sempre isso é uma verdade absoluta.

Segundo Farrington (2002), esses fatores de risco podem desenvolver comportamentos violentos em longo prazo, em contra partida, influenciam nas diferenças entre os indivíduos, pois pessoas sob as mesmas condições adquirem comportamentos mais ou menos violentos, há pessoas com maior tendência a cometer violência que outras, por isso não há que se falar em determinismo.

Debarbieux (2002) afirma que essa abordagem dos fatores de risco é importante para o estudo acerca da violência da escola, quando temos o intuito de analisar e identificar as variáveis pessoais, familiares, contextuais e estruturais, mas não devemos considerá-los como únicos e determinantes. Para o autor, fatores de ordem interna à escola, relativos à organização e funcionamento da instituição influenciam bastante na ocorrência dos casos de violência. Por isso, ele afirma, a violência na escola deve ser analisada de maneira macro e microssociológica.

A análise dos questionários remonta a esse questionamento de Debarbieux (2002). O conceito de violência de P3 aponta para os fatores internos e externos à escola. Para o docente, violência na escola corresponde à "falta e/ ou ao mau planejamento; falha na gestão e muita falha de educação; má criação". Isso demonstra 
uma descrença no planejamento pedagógico da sua instituição e no papel desempenhado pela gestão escolar. O uso do e/ou pelo depoente, aponta que dentro do planejamento dessa escola a violência não parece ser prioridade ou até mesmo considerada para o desenvolvimento das ações e projetos pedagógicos.

Para P3, a falha na gestão escolar determina a incidência da violência na escola, pois a falta de comprometimento e de ações de enfrentamento dessa situação contribui para o aumento da incidência de violência. Nesse caso, a visão do professor joga grande parte da responsabilidade da violência na escola para a gestão, eximindo-se da responsabilidade, do seu papel dentro da escola. Além das questões internas, $\mathbf{P 3}$ também ressalta uma falha na educação familiar, "má criação".

A estrutura familiar e a educação dentro da família influenciam nos casos de violência. Aqui a responsabilidade da família se evidencia, pois jovens que não possuem uma sólida estrutura familiar, isto é, com pais responsáveis e comprometidos com a orientação de seus filhos, estão na zona de risco de desenvolver um comportamento violento. Independentemente de sua classe social, a base familiar influencia no comportamento social dos sujeitos. Neste caso, a escola de $\mathbf{P 3}$ trata atende jovens de baixa renda, da periferia de uma cidade do interior, que em geral são considerados em situação de risco, afirmação confirmada pelo discurso de P3. O que demonstra certo preconceito com esse tipo de constituição familiar, uma afirmação que não deve ser determinante, pois como observamos, nem sempre fatores de risco de ordem familiar são motivadores de perfis violentos.

O discurso de $\mathbf{P 3}$ também nos faz refletir sobre o posicionamento de Abramovay et al. (2002) em relação à variação do conceito de violência dependendo do local e status de quem fala, pois o conceito deste docente aponta para o status de alguém que está de fora, isto é, que não tem responsabilidade nenhuma pelo problema.

Nesse sentido, com relação à definição de violência, o estudo de Abramovay et al. (2002) diferenciou a violência na escola em três aspectos: 1 . quanto à pessoa: agressões físicas e verbais, ameaças, violência sexual e uso de armas; 2 . quanto à propriedade (relativo aos roubos e furtos) e 3. quanto ao patrimônio (depredação do ambiente escolar). Ampliando o conceito de violência, a autora apresenta a conceituação de Charlot (1997 apud ABRAMOVAY et al., 2002), que divide a violência na escola em três níveis: uma que chama simplesmente de violência, relacionada a golpes, ferimentos, violência sexual, roubos, crimes, vandalismos; outra denominada de incivilidades, que se refere a humilhações, à falta de respeito e, por fim, a violência simbólica ou institucional, que corresponde à falta de interesse pela escola e as relações de poder na instituição. 
O conceito de Charlot aproxima-se dos conceitos de violência dos professores pesquisados. P1 e P4 consideram como violência as agressões físicas e verbais entre os sujeitos escolares. Já P2 e P5 definem violência como a falta de respeito que gera a indisciplina e a destruição do patrimônio escolar. Os conceitos de violência na escola desses professores se resumem aos dois primeiros níveis de violência descritos por Charlot, a denominada violência e as incivilidades, aproximando a violência do conceito de indisciplina escolar.

$\mathrm{Na}$ visão desses profissionais, violência na escola e indisciplina se confundem, pois apresentam as agressões e a constante falta de respeito como evento de violência. Fato este comprovado nas respostas da quarta pergunta, quando foi pedido que assinalassem os principais tipos de violência que ocorrem na escola. As respostas dos professores apontaram que o comportamento dos alunos é de total desrespeito dentro do ambiente escolar, tanto para com os professores, como para com a própria escola, traduzido na violência moral, nas agressões verbais e na depredação do ambiente escolar.

Diante dessa opinião dos professores, percebemos a necessidade de refletir um pouco sobre a distinção de violência e indisciplina sob a ótica de Aquino (1999), Giglio (1999) e Parra (2009). Etimologicamente, o termo indisciplina se relaciona ao comportamento transgressor de regras impostas por uma hierarquia, associada com desordem e rebeldia. Geralmente as escolas e os professores impõem determinadas regras de comportamento para viabilizar o funcionamento adequado da instituição. Os alunos apenas devem obedecer às normas, tendo um comportamento que escola e professores julgam adequados.

Há uma nítida relação de poder e força no estabelecimento dessas normas, por isso qualquer transgressão dos alunos é considerada indisciplina. Assim, podemos observar que a indisciplina está relacionada com questões internas e de natureza pedagógica da escola, influenciando principalmente na relação professor-aluno. Segundo Parra (2009, p. 9264),

A indisciplina significa o contrário à disciplina, é o estado de desordem, de desobediência e de rebeldia. A violência por outro lado, se constitui a partir do uso da força, ocorre um constrangimento físico e/ou moral. Nesse sentido ao comparar-se violência com a indisciplina na escola, há que se considerar uma distinção entre esses dois fenômenos.

Percebemos, assim, que a principal distinção de violência e indisciplina está relacionada ao uso da força e da dimensão que é dada aos dois fenômenos. Enquanto a indisciplina é considerada um fenômeno de ordem apenas interna, a violência assume um caráter mais amplo de natureza social, subsidiada pelo uso da força. Uma força que também pode ser extraída da relação de uma instituição ou de um professor que impõe regras disciplinares aos seus alunos. Será que im- 
por normas aos educandos também não é uma forma de violência institucional? Até que ponto as normas disciplinares impostas verticalmente levam em consideração os interesses e os direitos dos alunos?

Apesar de não ser o objetivo deste trabalho, entendemos que é necessário ampliar as discussões em torno do que os professores consideram como violência e indisciplina, observando qual é o contexto escolar e como o uso da força influencia no cotidiano da escola e no comportamento dos alunos, pois muitas vezes, a indisciplina em sala de aula pode gerar a violência, assim como a violência pode ser considerada uma indisciplina.

Em geral, observamos que a indisciplina está intimamente ligada ao modo como os professores e a escola se relacionam com os alunos, a postura pedagógica do docente influencia bastante no que ele considera como indisciplina na sala de aula.

Segundo Giglio (1999, p. 185), “fala-se da indisciplina dos alunos como a quebra de regras ou de modelos de conduta que não foram escritos e atuam de forma naturalizada" e que dispensam a revisão das práticas dos professores, bem como de toda a estrutura escolar. Entretanto, para a autora, é necessário buscar um novo sentido na organização institucional da escola que atenda às necessidades dos alunos, dos professores e da comunidade.

A importância de se repensar a escola também é ressaltada por Aquino (1999, p. 5) quando afirma que para superar o fracasso escolar é preciso rever algumas verdades que não alteram os rumos do cotidiano escolar, como por exemplo, o conceito de aluno desrespeitador. Para o autor, pensar na escola atual significa também "uma necessidade legítima de transformações no interior das relações escolares e, em particular, na relação professor-aluno".

Aquino (1999) afirma que para muitos o fracasso escolar está diretamente associado à indisciplina e ao baixo aproveitamento dos alunos e por isso devemos superar a ideia de uma escola disciplinadora, onde o medo e a submissão são os principais elementos que conduzem o comportamento dos alunos dentro da escola. Esse tipo de disciplina escolar é uma forma de violência institucional que prejudica o pleno desenvolvimento dos alunos, pois uniformiza e impede o florescer de todas as suas potencialidades.

Já quando pensamos em violência na escola, os questionamentos adquirem uma dimensão maior devido à natureza complexa do fenômeno. Segundo Parra (2009, p. 265), “A violência decorre de uma visibilidade maior, suas marcas são mais evidentes e de repercussão social mais ampla, o dano provocado possui um alcance social que vai do poder de polícia do Estado até o sistema de atendimento de saúde", nitidamente associa a violência a fatores exógenos à escola. 
Aquino (1998, p. 4) aponta que o problema da violência na escola não está ligado somente a fatores exógenos e sociais, mas também intimamente associado às relações de ordem interna, traduzido "por meio da apropriação de vetores de força por parte de seus atores constitutivos", o que muitas vezes faz com que a própria escola produza a violência, dita institucional.

Assim, podemos perceber que a indisciplina e a violência na escola são conceitos tênues e que de alguma forma se entrelaçam, pois quando tratamos a indisciplina como uma quebra de regras, a violência também pode ser considerada como um tipo de indisciplina.

Outro aspecto que obteve destaque nas respostas dos professores foi a violência moral, traduzida no preconceito, na discriminação, nos apelidos, nas humilhações, nas coações, nas ameaças e no bullying, considerado por Fante (2005) como um tipo de violência repetitiva que tem o intuito de constranger e perseguir outrem considerado diferente. Esse tipo de violência interfere diretamente no aspecto psicológico dos envolvidos, muitas vezes afastando os alunos da escola, excluindo-o do ambiente escolar.A escola deixa de ser um lugar prazeroso de convívio e formação humana, de promoção do conhecimento, para ser um local onde é semeada a exclusão e a degradação da dignidade humana.

Assim, podemos perceber que, de maneira geral, o discurso dos professores aponta para um conceito de violência que alia questões de natureza interna e externa à escola, demonstrando que aspectos sociais e pedagógicos contribuem para o desenvolvimento de comportamentos violentos na escola. O que possibilita refletir sobre a importância da presença do diálogo dentro das instituições e, consequentemente, das relações interpessoais entre os sujeitos escolares, possibilitando a melhoria das condições de aprendizagem no ambiente escolar.

Confirmando a relação da violência com a falta de diálogo, nos aproximamos do conceito de violência de Sposito (1998). Para a autora, "a violência é todo ato que implica a ruptura de um nexo social pelo uso da força. Nega-se, assim, a possibilidade da relação social que se instala pela comunicação, pelo uso da palavra, pelo diálogo e pelo conflito" (SPOSITO, 1998, p. 3). Neste caso, a violência está relacionada com uma força que nem sempre é visível ou palpável, como a força bruta da agressão física, pois a violência na escola também pode se instaurar institucionalmente nas suas relações internas, através de imposições verticalizadas e autoritárias.

Cabral e Lucas (2010, p. 22) também ressaltam a quebra do diálogo no cerne da violência na escola, considerando que "as violências na escola são relações nas quais não existe consenso, tolerância, oportunidade para o diálogo, para acordos alternativos". Assim, acreditamos que apesar de toda a complexidade do fenômeno da violência, o ambiente escolar pode desenvolver 
uma prática pedagógica dialógica que estimule o melhor entendimento entre os sujeitos escolares, favorecendo a mediação dos casos de violência.

Quando pensamos em diálogo, não estamos nos referindo ao simples ato de conversar, mas sim a uma proposta que contribua para a mudança de comportamento dos sujeitos envolvidos e para o desenvolvimento de uma práxis social que busque a transformação da situação de violência na escola. Para tanto, é necessário termos a compreensão dos diálogos que existem nas vozes de Bakhtin (1997), Bohm (1989, 1999) e Freire (1987).

\section{Sobre o diálogo}

Para Bohm (1989, p. 2), o diálogo "é o significado compartilhado assim criado, é a 'cola' ou o 'cimento' que mantém as pessoas e a sociedade unidas". A partir do diálogo, as pessoas criam um movimento de pensamento e comunicação coerentes, tanto em nível de percepção quanto de sentimentos, isto é, o diálogo possibilita um pensamento coletivo.

Para se chegar a esse diálogo, o autor aponta que primeiramente deve haver a suspensão das ideias individuais com o fim de se chegar a uma melhor compreensão do outro, pois os seres humanos possuem naturalmente pressupostos culturais previamente formados e por isso numa comunicação há forte tendência à fragmentação quando os sujeitos envolvidos querem impor sua opinião sobre determinado assunto. Já pelo método dialógico, as pessoas do processo comunicativo passam a perceber e a repensar seus pressupostos, emergindo daí, novas ideias.

Mariotti (2000, p. 4) afirma que no diálogo de Bohm (1989, 1999), “as ideias novas surgem por meio da cooperação, não pelo confronto”. Há uma relação sistêmica, cujo principal objetivo é aprender pela explicação, através de uma observação-participante. Não há, portanto, o intuito de emitir juízos de valor, pois "é antes de mais nada aprender a ouvir" (MARIOTTI, 2000, p. 5).

Em resumo, podemos compreender que na visão de Bohm (1989), o diálogo implica um processo de abertura e compreensão do outro, a fim de juntos criarem um movimento convergente de um pensamento coletivo, sempre buscando diminuir a fragmentação das relações humanas através do desenvolvimento da empatia e da cooperação.

Já para Bakhtin (1987), segundo Navarro (2005, p. 27), o diálogo se baseia no outro, "dialogar significa relacionar sentidos, ser construído como sujeito a partir do outro". Refletir sobre o olhar do outro possibilita a renovação de sentidos e de posturas individuais, num movimento sistêmico e inacabado, pois sempre há possibilidades novas. Nessa perspectiva, o diálogo é condição da essência 
humana, pois todo discurso traz em si uma carga de pensamentos alheios, dentro de um contexto temporal. Assim, os sujeitos são construídos e reconstruídos num movimento contínuo.

O diálogo em Bakhtin (1987) se constitui na heterogeneidade, na pluralidade das vozes que formam o discurso. A ausência dessa pluralidade impossibilita o diálogo, pois não há o confronto com o outro, um confronto que permite, segundo Navarro (2005), construir consensos, situações harmoniosas e criativas. Não há número limitado de sujeitos, pois enunciados distantes no tempo e no espaço podem participar do mesmo movimento dialógico. Por isso, "expressa profunda atenção às diferenças, variedades e alteridades entre os povos, textos, ideologias, linguagens, buscando sempre como se articulam e se relacionam" (NAVARRO, 2005, p. 29).

A compreensão também é essencial ao diálogo de Bakhtin (1987). Navarro (2005) afirma que através da compreensão ativa encontramos o novo, criamos, pois ao dialogarmos com o outro, o reconhecemos como outro e podemos percebê-lo de um local que este não pode, emitindo juízos de valor a partir de nossas crenças. Quando não encontramos o novo no encontro com o outro, não há diálogo, "significa não reconhecermos ou anularmos o outro, só vemos a nós próprios, o já conhecido" (NAVARRO, 2005, p. 67).

Para Bakhtin (1987), segundo Navarro (2005), ser significa comunicar-se e a vida é inacabada, não há ponto final, por isso, o diálogo é inerente aos seres humanos que se encontram em processo permanente de construção.

Como podemos perceber nas concepções de diálogo até então apresentadas, este permite a aproximação dos seres humanos, une para agregar valores, privilegia o coletivo e as relações interpessoais, onde, numa relação mútua, os sujeitos atuam para construírem seus conhecimentos, se transformando e transformando a sociedade, e nela, segundo Mariotti (2000), não há vencedor e perdedor, apenas ganhadores. Assim, a postura dialógica é uma possibilidade real de mediação da violência na escola, aproximando os sujeitos escolares e permitindo a solução pacífica de todos os conflitos.

O diálogo em Freire (1987) convida os seres humanos a terem uma nova postura perante o outro e a sua realidade, através da problematização e da conscientização, os sujeitos são desafiados pela justa raiva a desenvolver uma nova práxis. E dentro do ambiente escolar, o autor propõe uma prática pedagógica baseada na confiança e no respeito, onde educador e educando irão construir coletivamente o conhecimento.

Com os conceitos de opressor e oprimido, o autor nos leva a refletir sobre nossa relação com o outro e de como uma situação opressora pode se estabelecer no ambiente escolar. Um ambiente marcado por relações hierárquicas onde 
a condição de opressor ou oprimido pode ser superada com a comunhão dos homens para serem mais, baseada no respeito, na confiança e no amor. Segundo Gutiérrez (2008, p. 58), o caráter humanista de Freire o levou a reconhecer que "não é a razão, mas sim a emoção e o amor que tornam possível a relação de convivência e da aceitação mútua".

Assim, Freire (1987) propõe uma educação horizontal permeada pelo diálogo, construído através da problematização da realidade, ou seja, a reflexão da realidade dentro da própria realidade e da conscientização, o conhecimento de sua condição no mundo. Uma educação do ser em comunhão com o outro, mediatizados pelo mundo, sendo sujeito de sua própria educação e não objeto desta.

O importante, do ponto de vista de uma educação libertadora, e não "bancária", é que, em qualquer dos casos, os homens se sintam sujeitos de seu pensar, discutindo o seu pensar, sua própria visão do mundo, manifestada implícita ou explicitamente, nas suas sugestões e nas de seus companheiros. (FREIRE, 1987, p. 120).

Outro ponto importante da educação dialógica de Freire (1987) diz respeito ao permanente processo de ação-reflexão dentro da prática pedagógica, o educador deve buscar refletir sua prática sistematicamente, não significa agir para depois refletir, mas sim buscar a reflexão no momento da ação.Essa reflexão permite ao educador um maior entendimento do contexto de sua prática e de como pode buscar alternativas para solucionar situações-problemas.

Essa postura de Freire (1987) reflete nitidamente o tipo de educação em que ele acreditava. Uma educação libertadora, centrada na dialogicidade e na visão humanista dos seres humanos, onde o educador não é o único detentor do conhecimento, ao contrário, deve apoiar sua prática no respeito e na confiança, buscando o aprendizado mútuo junto de seus alunos.

Como podemos perceber, Freire (1987), Bohm (1989) e Bakhtin (1987 apud NAVARRO, 2005) sugerem diferentes tipos de diálogo. Enquanto os dois primeiros propõem uma postura dialógica, Bakhtin (1987 apud NAVARRO, 2005) afirma que o diálogo faz parte do ser humano. Entretanto, segundo Navarro (2005, p. 36), os três autores citados "sinalizam a pertinência de tornarmos a ciência da dialogia como fundamento da vida". Através do diálogo, os seres humanos podem se construir permanentemente. O diálogo é uma necessidade da condição humana.

Bohm, Freire e Bakhtin compartilham a tese de que a vida é uma construção de um grande diálogo e que nós, seres humanos somos seus participantes ativos. Diante disso, acreditamos que situações dialógicas podem permitir transformações pertinentes no tocante às formas de relacionamento humano atuais, possibilitando novas maneiras de pensar, conhecer e agir. (NAVARRO, 2004, p. 35). 
Viver é um constante desafio, pois somos cotidianamente provocados por novas e variadas situações. Navarro (2005, p. 37) sugere que o diálogo pode ser um recurso que possibilita um maior entendimento de nós próprios e das questões de natureza social, promovendo "uma maior compreensão na maneira como vislumbramos e enfrentamos nossos problemas e necessidades".

Assim, uma sociedade construída pelo diálogo será mais sensível e humana, suas diferenças serão exaltadas e valorizadas pelo respeito mútuo. Portanto, é imprescindível estimular o diálogo dentro da sociedade e da escola, buscando a construção de novos valores, mais justos, igualitários e coletivos.

Com relação à violência na escola, acreditamos que o diálogo proposto por Freire (1987), apoiado pelo diálogo proposto por Bohm (1989, 1999) e Bakhtin (1997 apud NAVARRO, 2005), possibilita maior mediação dos casos de violência, pois a partir da problematização e da conscientização da violência na escola, os sujeitos escolares podem buscar alternativas que viabilizem a mudança, reconhecendo o outro e suas diferenças, aprendendo e se transformando num processo contínuo de interações e integrações. Uma transformação, porém, que não implica necessariamente acabar com os casos de violência, mas que propõe um novo tratamento ao tema, que ao invés de torná-los casos de polícia ou de exclusão, pode agregar valores e construir novos sujeitos.

\section{O diálogo e a mediação da violência na escola}

Andrade (2011) aponta que a perspectiva freireana pode nortear intervenções adequadas nas situações de violência na escola, através do desenvolvimento nos educadores da Competência Inter-Relacional (CIR), que possibilita tratar as situações de violência de maneira bem sucedida,com base na articulação do "saber conviver e saber ensinar a conviver" (ANDRADE, 2011, p. 92).

Com o fim de melhorar a convivência na escola, o autor afirma que a competência (CIR) envolve tanto a conduta social quanto pedagógica do professor, sendo concebida em cinco dimensões indissociáveis e articuláveis, são elas: comportamental (postura adequada conforme as metas de uma ação ou tarefa), cognitiva (capacidade de analisar as próprias estratégias de aprendizagem, os próprios conceitos), afetiva (capacidade de experimentar, identificar e expressar sentimentos), social (relativa às metas de interação social) e desiderativa (identificar desejos que motivam a própria conduta e a das pessoas com quem se convive na escola).

Revisitando a literatura de Freire, Andrade (2011) associa a competência de gerar os conflitos na escola com a postura dialógica descrita nos livros Professora sim, tia Não e Pedagogia da Autonomia, destacando como principais elementos 
a amorosidade, a paciência, a tolerância, o rigor metodológico, o respeito, a abertura afetiva ao novo e o comprometimento. Tais elementos caracterizam um professor que tem a capacidade afetiva de acolher seus alunos, compreendendoos na diversidade e procurando desenvolver técnicas que melhorem o processo de ensino-aprendizagem e a convivência dentro do ambiente escolar.

A competência (CIR) de Andrade (2011) também implica a capacidade dos professores de lidarem com os diferentes tipos de sentimentos dentro da diversidade que o universo escolar possibilita.Quando questionamos aos professores sobre a reação deles diante dos casos de violência, em síntese, responderam que procuraram ficar calmos para contornar a situação, para mostrar a verdade dos fatos ocorridos; para retirar os envolvidos do motim e que o fato violento causou espanto.

A recorrência das palavras tranquilo e calmo demonstra que na visão dos docentes a postura adequada para tratar os casos de violência está intimamente ligada ao controle emocional, pois quando se consegue manter a calma e superar o abalo que a violência causa, se consegue tomar uma atitude condizente com o que a realidade necessita.

O fato de permanecerem calmos mobiliza diversas dimensões da Competência Inter-Relacional de Andrade (2011), pois possibilita uma melhor análise da situação de violência e, consequentemente, a tomada de atitude é a mais acertada, além de conseguirem expressar e experimentar de maneira adequada todos os sentimentos envolvidos e que motivam a conduta em questão, permitindo uma postura voltada para uma interação social positiva.

O professor codificado de $\mathbf{P} 2$, por exemplo, respondeu que sua reação foi "retirar os envolvidos do motim". Podemos inferir que a situação de violência tratou-se de uma briga, pois motim significa confusão em geral de natureza agressiva e que o docente agiu impulsivamente, reagiu de maneira imediata aos fatos, tentando acabar com a agitação. Mas será que apenas "retirar os envolvidos" resolve, de fato, a situação? Momentaneamente, sim, pois acaba com o tumulto, entretanto, não soluciona o problema. Não mobiliza sentimentos que conduzam a conscientização dos envolvidos e, consequentemente, modifiquem a realidade que gerou o tumulto.

Perguntamos também aos docentes como devemos agir para contornar os casos de violência na escola. No geral, responderam que é necessário manter a calma e dialogar, chamando os envolvidos para conversar e aconselhar. Aqui a necessidade do diálogo com os envolvidos na violência é bastante evidenciada, pois quando se chama para conversar e aconselhar, há um sentimento de abertura ao outro com o fim de estimular a compreensão, a empatia e a convivência pacífica. E quando pensamos na convivência entre professor e aluno, esse comportamento os aproxima, possibilita a educação horizontal proposta por Freire (1987). 
Esta pergunta também mobilizou respostas de natureza pedagógica: "trabalho constante sobre disciplina, sobre as normas da escola, fornecer cursos de formação, palestras, filmes etc.” (P2 e P5). Neste caso, o planejamento pedagógico da escola é exaltado como uma possibilidade de gestão da violência, pois influencia diretamente no comportamento de todos os sujeitos escolares. Segundo Tognetta et al. (2010, p. 26), "A organização do trabalho pedagógico com vistas ao desenvolvimento afetivo e cognitivo e, portanto, moral, pressupõe que suas bases estejam alicerçadas na cooperação e no respeito mútuo".

Esse fazer pedagógico baseado na cooperação e no respeito também condiz com o pensamento dialógico de Freire (1989), quando propõe uma educação centrada na constante ação-reflexão dos sujeitos escolares e no processo de colaboração mútua entre educador e educando.

Por fim, analisando as respostas dadas para as duas últimas perguntas ${ }^{1}$, percebemos que na opinião dos docentes a violência interfere bastante no bem-estar das aulas e na aprendizagem dos alunos e que as ações pedagógicas são as maiores aliadas do processo de mediação da violência na escola. Um cotidiano escolar marcado pela violência altera a rotina das escolas, causa o afastamento dos alunos e o desestímulo dos professores.

Sem a pretensão de aprofundar as discussões sobre o cotidiano, mas somente com a intenção de refletir sobre a importância do fazer pedagógico para a mediação da violência no dia-a-dia das escolas, vale a pena analisar a concepção de cotidiano de Certeau. Segundo Duran (2007), três pontos da teoria de Certeau se destacam: o fato dele acreditar na capacidade inventiva dos mais fracos, o rigor conceitual e a crítica reflexivo-histórica e o seu compromisso em narrar práticas comuns.

Duran (2007) afirma que, para Certeau, o cotidiano é construído também pelo fazer criativo de autores anônimos, que reinventam a lógica imposta pelo sistema. Quando voltamos nosso olhar para as respostas dos professores pesquisados, percebemos que a prática pedagógica do cotidiano de violência na escola deve estar em constante processo de construção e reconstrução, "unir forças e planejar novas ações pedagógicas" (resposta de P6), baseadas no diálogo, fazem parte do fazer educativo criativo.

Para Tognetta et al. (2010, p. 30), o processo de prevenção e mediação da violência na escola exige a construção de um ambiente escolar cooperativo que possibilite:

\footnotetext{
${ }^{1}$ Como a violência interfere no cotidiano escolar e como pode ser minimizada? A escola desenvolve (eu) alguma ação visando prevenir a violência na escola?
} 
Favorecer a quantidade e qualidade da interação social; minimizar o autoritarismo do adulto, evitando pressões e coerções, assim como o uso de recompensas e punições; incentivar os alunos a fazerem por si mesmos tudo aquilo que já são capazes, tendo oportunidades de realizar escolhas, tomar decisões, resolver seus problemas e expressar-se livremente; empregar uma linguagem construtiva; conceber o conhecimento como algo a ser investigado, reinventado ou descoberto pelo sujeito e não transmitido como verdade absoluta; estimular a ação sobre o objeto do conhecimento, assim como o estabelecimento de relações, oportunizando (sic) discussões e reflexões sobre situações-problema; trabalhar a expressão dos sentimentos e a resolução dos conflitos interpessoais por meio do diálogo; utilizar as sanções por reciprocidade quando isso for necessário para revalidar normas e princípios.

Tognetta et al. (2010) propõem então a construção de uma escola plenamente fundada no diálogo, sem punições autoritárias, impostas pelo uso da força hierárquica, mas sim, um ambiente em que todos os sujeitos escolares tenham vOz e possam contribuir, seja no processo ensino-aprendizagem ou na solução de problemas. Através desse permanente diálogo dentro da escola, vislumbra-se a possibilidade de prevenção e mediação da violência com um envolvimento e participação de todos, ligados pelos sentimentos de responsabilidade e amor pela escola.

Segundo os professores, as escolas pesquisadas desenvolvem ações pedagógicas voltadas para o enfrentamento das situações de violência com o intuito de estabelecer essa atmosfera cooperativa descrita por Tognetta et al. (2010). São desenvolvidos projetos extracurriculares, palestras e reuniões, junto com o apoio da Secretaria de Educação do município de Mossoró, visando implantar uma atmosfera de harmonia entre todos os segmentos da escola.

Uma harmonia que, de acordo com as respostas dadas, não prescinde da participação ativa de todos os atores escolares, havendo um forte desejo de integrar toda a comunidade escolar, principalmente aproximando a família da escola, para que os pais também possam contribuir com o desenvolvimento de uma educação dialógica, base da educação popular. Segundo Gadotti (1998, p. 2),

Um dos princípios originários da educação popular tem sido a criação de uma nova epistemologia baseada no profundo respeito pelo senso comum que trazem os setores populares em sua prática cotidiana, problematizando-o, tratando de descobrir a teoria presente na prática popular, teoria ainda não conhecida pelo povo, problematizando-a, incorporando-lhe um raciocínio mais rigoroso, científico e unitário.

Gadotti (1998) afirma também que a educação popular proposta por Paulo Freire semeou as principais ideias de uma educação emancipadora, capaz de transformar a realidade social vigente. Vale (2001) também discute a importância 
da educação popular dentro da escola pública, analisando a trajetória de projetos implementados, refletindo exaustivamente a viabilidade de construção da escola pública popular.

A escola popular não é aquela a que todos têm acesso apenas. A extensão da escola para todos não garante o seu caráter popular, basta lembrarmos que esse foi um dos princípios defendidos pela escola pública burguesa- a universalidade do ensino. A escola pública popular está ligada, portanto, à luta desses segmentos por uma mudança qualitativa da escola, conferindo-lhe uma nova função social. (VALE, 2001, p. 56).

Assim, acreditamos que uma escola pública popular construída sobre bases sólidas dialógicas pode contribuir para mediar os casos de violência na escola, aproximando-a da comunidade, estimulando a cooperação e o entendimento entre os sujeitos escolares, por intermédio da constituição de valores coletivos e de solidariedade.

\section{Considerações finais}

A violência na escola é um fenômeno social bastante complexo. Instaurada pelo uso da força e pela quebra do diálogo, interfere diretamente no cotidiano escolar, por isso, precisamos buscar alternativas que contribuam para a mediação dos casos de violência. Acreditamos, ainda, que o diálogo é a alternativa mais adequada para o tratamento dessa violência, pois uma postura dialógica possibilita a problematização da realidade e a conscientização dos indivíduos, a fim de transformação dessa mesma realidade, através de uma mudança de comportamento.

Como podemos perceber pelas respostas dos professores, o diálogo dentro da escola é plenamente possível e pode melhorar a convivência entre os sujeitos escolares, permitindo maior aproximação interpessoal e a construção de um ambiente escolar baseado no respeito e na colaboração, onde o conhecimento é buscado coletivamente.

Os sujeitos pesquisados evidenciam que uma postura dialógica de abertura ao outro, através da mobilização de sentimentos positivos e de um fazer pedagógico criativo dentro do ambiente escolar, pode contribuir para a prevenção e intervenção significativa na violência dentro das escolas. Por isso, acreditamos que o diálogo pode contribuir para a mediação da violência na escola, estabelecendo novas relações e construindo novos valores, pois a violência na escola é um estado e não uma característica, o que pode ser modificado através de novas posturas e oportunidades. 


\section{Referências}

ABRAMOVAY, M. et al.Violência nas escolas. Brasília: UNESCO, Coordenação DST/ AIDS do Ministério da Saúde, Secretaria de Estado dos Direitos Humanos do Ministério da Justiça, CNPq, Instituto Ayrton Senna, UNAIDS, Banco Mundial, USAID, Fundação Ford, CONSED, UNDIME, 2002.

ANDRADE, F. C. B. Competência docente para gestão de conflitos na escola: inspirações freireanas. In: SANTOS, J. M. C. T. (Org.). Paulo Freire: teorias e práticas em Educação Popular- escola pública, inclusão, humanização, Fortaleza: Edições UFC, 2011. p. 90-105.

AQUINO, J. G. A indisciplina e a escola atual. Revista da Faculdade de Educação, São Paulo, v. 24, n. 2, p. 181-204, jul./dez. 1998. DOI: 10.1590/S0102-25551998000200011

Autoridade docente, autonomia discente: uma equação possível e necessária. AQUINO, J. G. (Org.). Autoridade e autonomia na escola: alternativas teóricas e práticas. São Paulo: Summus, 1999. p. 131-154.

BAKHTIN, M. Estética da criação verbal: os gêneros do discurso. 2. ed. São Paulo: Martins Fontes, 1997.

BAUMAN, Z. Modernidade líquida. Tradução de Plínio Dentzien. Rio de Janeiro: Jorge Zahar, 2001.

2008.

. Medo líquido. Tradução de Carlos Alberto Medeiros. Rio de Janeiro: Jorge Zahar,

BOHM, D. Diálogo: comunicação e redes de convivência. Lisboa: Gradiva, 1989.

On dialogue. London: Routledge, 1999.

BRASIL. Lei no 9.394, de 20 de dezembro de 1996. Estabelece as Diretrizes e Bases da Educação Nacional. Diário Oficial da União, Brasília, 23 dez. 1996.

2000 .

Parâmetros Curriculares Nacionais: Ensino Médio. Brasília: MEC/SEMTEC,

Ministério da Educação. Reestruturação e expansão do Ensino Médio no

Brasil, MEC, 2008. Disponível em: <http://www.observatoriodaeducacao.org.br/images/ publicacoes/pdfs/emmec.pdf> Acesso em: 20 out. 2011.

Diretrizes Curriculares para o Ensino Médio. Brasília, 2011.

CABRAL, S. R.; LUCAS, S. M. L. Violência nas Escolas: desafio para a prática docente. Rio de Janeiro: Gramma, 2010.

DEBARBIEUX, E. Violências nas escolas: divergências sobre palavras e um desafio político. In: DEBARBIEUX, E.; BLAYA, C. B. (Orgs.). Violência nas escolas e políticas públicas. Brasília: UNESCO, 2002. p. 59-92.

DURAN, M. C. G. Maneiras de pensar o cotidiano com Michel de Certeau. Diálogo Educacional, Curitiba, v. 7, n. 22, p. 115-128, set./dez. 2007. 
FANTE, C. Fenômeno bullying: como prevenir a violência nas escolas e educar para a paz. Campinas: Versus, 2005.

FARRINGTON, D. P. Fatores de risco para violência juvenil. In: DEBARBIEUX, E.; BLAYA, C. Violência nas escolas e políticas públicas. Brasília: UNESCO, 2002. p. 25-58.

FREIRE, P. Pedagogia do oprimido. Rio de Janeiro: Paz e Terra, 1987. p. 183-199.

GADOTTI, M. Para chegar lá juntos e em tempo. Caminhos e significados da educação popular em diferentes contextos. REUNIÃO ANUAL DA ANPED, 21., 1998, Caxambu. Anais... Caxambu: ANPED, 1998.

GIGLIO, C. M. B. A violência escolar e o lugar da autoridade: encontrando soluções partilhadas. In: AQUINO, J. G. (Org.). Autoridade e autonomia na escola: alternativas teóricas e práticas. São Paulo: Summus, 1999. p. 183-199.

GUTIÉRREZ, F. A dimensão humana de Paulo Freire. In: TORRES, C. A. et al. (Orgs.). Reinventando Paulo Freire no século 21. São Paulo: Instituto Paulo Freire, 2008. p. 57-90.

MARIOTTI, H. Diálogo: um método de reflexão conjunta e observação compartilhada da experiência. São Paulo, 2000. Disponível em: <http://www.teoriadacomplexidade.com.br/ textos/dialogo/Dialogo-Metodo-de-Reflexao.pdf.>. Acesso em: 22 out. 2011.

MINAYO, M. C. de S. O desafio da pesquisa social. In: DESLANDES, S. F.; GOMES, R.; MINAYO, M. C. de S. (Orgs.). Pesquisa social: teoria, método e criatividade. 28. ed. Petrópolis: Vozes, 2009. p. 9-29.

NAVARro, A. Diálogos e reflexão. 2005. 187 f. Tese (Doutorado em Educação) Universidade Federal do Rio Grande do Norte, Natal, 2005.

OLIVEIRA, M. B. F. de. Compreendendo e interpretando práticas discursivas: (re)visitando orientações bakhtinianas. OLIVEIRA, M. B. F. de; ALVES, M. da P. C.; SILVA, M. P. da. (Orgs.). Linguagem e práticas sociais: ensaios e pesquisas. Natal: EDUFRN, 2008. p. 11-23.

ORLANDI, E. P. Análise do discurso: princípios e procedimentos. Campinas: Pontes, 2005.

PARRA, S. Indisciplina e violência na escola e o processo de Ensino-aprendizagem: algumas considerações a partir da organização do trabalho pedagógico. In: IX CONGRESSO NACIONAL DE EDUCAÇÃO, 9.; ENCONTRO SUL BRASILEIRO DE PSICOPEDAGOGIA, 3., 2009, Curitiba. Anais... Curitiba: PUC/PR, 2009. p. 9262-9275.

RICHARDSON, R. J. Pesquisa social: métodos e técnicas. São Paulo: Atlas, 2010.

SPOSITO, M. P. A instituição escolar e a violência, 1998. Disponível em: <www.iea.usp. br/observatorios/educacao>. Acesso em: 13 dez. 2011.

TEIXEIRA, M. C. S.; PORTO, M. do R. S. Violência, insegurança e imaginário do medo. Cadernos Cedes, Campinas, v. 19, n. 47, p. 51-66, dez. 1998. DOI: 10.1590/S010132621998000400005

TOGNETTA, L. R. P. et al. Um panorama geral da violência na escola e o que se faz para combatê-1a. Campinas: Mercado de Letras, 2010. v. 1. 
VALE, A. M. do. Educação popular na escola pública. São Paulo: Cortez, 2001.

ZIBAS, D. A reforma do Ensino Médio no Chile: vitrina para a América Latina? Cadernos de Pesquisa, São Paulo, n. 115, p. 233-262, jan./abr. 2002. DOI: 10.1590/S010015742002000100010

Recebido em 04/03/2012

Versão final recebida em 11/09/2012

Aceito em 02/10/2012 